\title{
REGy ablation impedes dedifferentiation of anaplastic thyroid carcinoma and accentuates radio-therapeutic response by regulating the Smad7-TGF- $\beta$ pathway
}

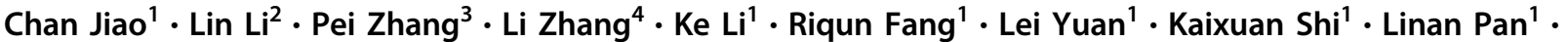

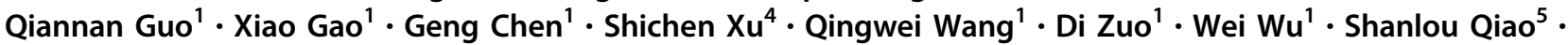 \\ Xiaoshuang Wang ${ }^{1} \cdot$ Robb Moses ${ }^{6} \cdot$ Jianru Xiao ${ }^{2} \cdot{\text { Lei } \mathrm{Li}^{1} \cdot \text { Yongyan Dang }}^{1} \cdot \mathrm{Xiaotao}_{\mathrm{Li}^{1,6}}$
}

Received: 27 January 2019 / Revised: 17 May 2019 / Accepted: 30 May 2019 / Published online: 26 June 2019

(c) The Author(s), under exclusive licence to ADMC Associazione Differenziamento e Morte Cellulare 2019. This article is published with open access

\begin{abstract}
Anaplastic thyroid cancer (ATC) is the most aggressive human thyroid malignancy, characterized by dedifferentiation and resistance to radioiodine therapy. The underlying mechanisms regulating ATC dedifferentiation are largely unknown. Here, we show that REG $\gamma$, a noncanonical proteasome activator highly expressed in ATC, is an important regulator of differentiation in ATC cells. Ablation of REG $\gamma$ significantly restored expression of thyroid-specific genes, enhanced iodine uptake, and improved the efficacy of ${ }^{131} \mathrm{I}$ therapy in ATC xenograft models. Mechanistically, REG $\gamma$ directly binds to the TGF- $\beta$ signaling antagonist Smad7 and promotes its degradation, leading to the activation of the TGF- $\beta$ signal pathway. With gain- and loss-of-function studies, we demonstrate that Smad7 is an important mediator for the REG $\gamma$ function in ATC cell dedifferentiation, which is supported by expression profiles in human ATC tissues. It seems that REG $\gamma$ impinges on repression of thyroid-specific genes and promotion of tumor malignancy in ATC cells by activating the TGF- $\beta$ signal pathway via degradation of Smad7. Thus, REG $\gamma$ may serve as a novel therapeutic target for allowing radioiodine therapy in anaplastic thyroid cancer patients with poor prognosis.
\end{abstract}

Co-first authors: Chan Jiao, Lin Li

Edited by J.P. Medema

Supplementary information The online version of this article (https:// doi.org/10.1038/s41418-019-0367-9) contains supplementary material, which is available to authorized users.

Lei $\mathrm{Li}$

11lkzj@163.com

Yongyan Dang

yydang@bio.ecnu.edu.cn

$\triangle$ Xiaotao Li

xiaotaol@bcm.edu

1 Shanghai Key Laboratory of Regulatory Biology, Institute of Biomedical Sciences, School of Life Sciences, East China Normal University, 500 Dongchuan Road, Shanghai 200241, China

2 Department of Orthopedic Oncology, Changzheng Hospital, The Second Military Medical University, 415 Fengyang Road, Shanghai 200003, China

\section{Introduction}

Anaplastic thyroid cancer (ATC) is one of the most deadly human diseases. Due to its invasive nature and resistance to radiotherapy, ATC has an extremely low cure rate with a median survival of less than 6 months [1], responsible for more than half of all thyroid cancer deaths [2]. However, patients with differentiated thyroid carcinoma have an excellent 10 -year survival ranging

3 Department of Pathology, the Second Chengdu Municipal Hospital, Chengdu 610017, China

4 Jiangsu Institute of Nuclear Medicine, Key laboratory of Nuclear Medicine, Ministry of Health, 20 Qian Rong Road, Wuxi, Jiangsu 214063, China

5 Institute of Life \& Health Sciences, Chubu University, 1200 Matsumoto-cho, Kasugai, Aichi 487-8501, Japan

6 Department of Molecular and Cellular Biology, Dan L. Duncan Cancer Center, Baylor College of Medicine, One Baylor Plaza, Houston, TX 77030, USA 
between 80 and 95\% [3]. Radioactive iodine therapy improves the survival rate of patients with differentiated metastastatic thyroid cancer. The sodium iodide symporter (NIS), a transmembrane glycoprotein in the thyroid follicular cells, catalyzes the accumulation of iodide in the thyroid gland, allowing the treatment of differentiated thyroid cancers by radioactive iodine [4]. However, ATC fails to express adequate amounts of thyroid-specific genes, primarily due to NIS [5], leading to its resistance to radioiodine therapy. Therefore, innovative approaches for recovery of NIS expression in poorly differentiated thyroid cancers might promote therapy via iodine uptake [6].

TGF- $\beta$ functions as a tumor promoter through increasing tumor cell invasion and metastasis in late-stage cancers. TGF- $\beta 1$ is overexpressed in ATC and silencing TGF- $\beta 1$ inhibits cell migration and invasion of ATC cells [7]. Smad3 activation inhibits expression of Pax8 and its DNAbinding activity, mediating TGF- $\beta$-induced downregulation of NIS in thyroid follicular cells [8]. BRAF appears to induce secretion of TGF- $\beta$ in human PTC and inhibit NIS expression [9], substantiating that TGF- $\beta$ plays an important role in thyroid cancer progression.

REG $\gamma$ (also known as PA28 $\gamma$, PSME3, Ki antigen) belongs to the $11 \mathrm{~S}$ family of proteasome activators to promote ubiquitin and ATP-independent degradation of proteins $[10,11]$. REG $\gamma$ regulates cell cycle, inflammation, angiogenesis, and additional biological processes [12-16]. In addition, REG $\gamma$ is overexpressed in several tumors, including thyroid cancer, displaying oncogenic actions [1719]. However, it is unclear if overexpressed REG $\gamma$ in ATC promotes its malignancy.

In this study, we demonstrate that REG $\gamma$ enhances dedifferentiation of ATC cells. Depletion of REG $\gamma$ restored the expression of thyroid-specific genes in ATC cells and improved radioiodine uptake in vitro and in vivo, therefore, improving ${ }^{131} \mathrm{I}$ therapy in ATC xenograft tumors. REG $\gamma$ mediates upregulation of the TGF- $\beta$ pathway by degrading Smad7, since inactivation of Smad7 prevents the recovery of thyroid-specific genes in REG $\gamma$-deficient ATC cells. Thus, inhibition of the REG $\gamma$ proteasome might be a promising approach for ATC patients.

\section{Methods}

\section{Cells}

K18 ATC and HEK293T cells were purchased from American Type Culture Collection (ATCC, USA). SW1736 ATC was from James A. Fagin's laboratory. The REG $\gamma$ knockdown stable cell lines were generated by integration of retroviral ShRNA vector specific for REG $\gamma$ to produce ShR (ShRNA against REG $\gamma$ ) or a negative control from OriGene (Rockville, MD) to produce ShN (ShRNA as a negative control) cells. ATC cell lines and HEK293T cell line were cultured in the 1640 and DMEM medium supplied with $10 \%$ fetal bovine serum (Gibco), respectively. The 293-REG $\gamma$ inducible cell lines were previously generated.

\section{Plasmids, constructs, and expression}

HA-REG $\gamma$ (pcDNA3.1), Flag-Smad7 (pcDNA3.1), PSG5HA-Smad7, plvx-GFP-Smad7, plvx-Luc-G418, and NIS promoter luciferase (NIS-Luc) reporter plasmid (pGL2Basic) containing the $-2000 /+375$ sequence of NIS promoter were constructed in our laboratory. Smad3 siRNA (F5'-CCAGUGACCACCAGAUGAA-3') and Smad7 siRNA (F-5'-CUCUCUGGAUAUCUUCUAUTT-3' and R-5'AUAGAAGAUAUCCAGAGAGTT-3') were synthesized by Genepharma. Plasmids or siRNA were transfected to different cells and cultured for $36 \mathrm{~h}$ or $72 \mathrm{~h}$.

\section{In vitro ${ }^{131}$ I uptake of ATC cells}

Overall, $5 \times 10^{5} \mathrm{ShN}$ and ShR ATC cancer cells (SW1736 and K18) were plated in triplicates in 12-well plates. After washing with cold HBSS three times, cells were incubated for the indicated time at $37^{\circ} \mathrm{C}$ with $1 \mathrm{ml}$ of HBSS containing $1 \mu \mathrm{Ci}$ carrier-free $\mathrm{Na}^{131} \mathrm{I}$ and $10 \mu \mathrm{M}$ NaI. In control groups, cells were treated with $300 \mu \mathrm{M} \mathrm{NaClO}$, a competitive inhibitor of NIS, for $30 \mathrm{~min}$ to determine the nonspecific radioiodine uptake. Then, cells were washed with ice-cold HBSS for three times, lysed in $1 \mathrm{ml} 0.33 \mathrm{M} \mathrm{NaOH}$. The radioactivity was measured with a Perkinelmer 2470 gamma-counter.

\section{Luciferase assays}

SW1736 and K18 ATC cells were washed with cold PBS three times after transfection with NIS-Luc reporter for $36 \mathrm{~h}$, harvested in the lysis buffer provided in the Luciferase Assay Kit (Promega). After one cycle of freezing and thawing, the cell lysates were centrifuged at $12,000 \mathrm{rpm}$ for $10 \mathrm{~min}$ at $4{ }^{\circ} \mathrm{C}$. Then $20 \mu \mathrm{l}$ of supernatant was added to an equal amount of luciferase assay substrate. Luminescence was measured as relative light units using the LUMIstar OPTIMA (BMG Labtech) illuminometer.

\section{Western blot analysis, immunoprecipitation, and in vitro proteolytic analysis}

Cells were collected in NP40 lysis buffer and minced tissues were lysed in RIPA buffer on ice for $15 \mathrm{~min}$. For NP40 lysed samples, protein concentrations were determined by BCA assay kit (Beyotime, China). Equal amount of proteins 
were run on a $10-12 \%$ SDS-PAGE, transferred to a nitrocellulose membrane (Millipore, MA, USA), and then immunoblotted with the NIS (Millipore and Proteintech 24324-1-AP), Pax8 (Millipore and Bioworld BS3459), REG $\gamma$, p-Smad3, Smad3 (Proteintech), Smad7 (Abcam ab55493 and Proteintech), or $\beta$-actin antibodies (CST 3102 and Sigma A5441) overnight. After incubation with secondary fluorescent antibodies for $1 \mathrm{~h}$, the antibody-bound proteins were analyzed by a fluorescent western blot imaging system (Odyssey).

For co-immunoprecipitation assay, HEK293 cells were transiently transfected with plasmids expressing pcDNA3.1HA-REG $\gamma$ and pcDNA3.1-Flag-Smad7 for $48 \mathrm{~h}$. Then, cells were harvested in CHAPS lysis buffer. Extracts were incubated overnight with $2.5 \mu \mathrm{g}$ of anti-HA or anti-Flag (Santa Cruz Biotechnology, Heidelberg, Germany) antibody in the presence of Protein $G$ beads from a Protein $G$ Immunoprecipitation kit (Sigma-Aldrich, Buchs, Switzerland). Complexes were washed, denatured, and eluted for western blot analysis.

For in vitro proteolytic analysis, Smad7 protein was generated by in vitro translation [10]. The protein degradation experiment was conducted by incubating Smad7, $20 \mathrm{~S}$ proteasome (Boston Biochem), and purified REG $\gamma$ for $3-6 \mathrm{~h}$ in $25-\mu \mathrm{l}$ reaction volume at $30^{\circ} \mathrm{C}$ with appropriate controls. The results were analyzed by western blotting.

\section{Quantitative real-time PCR}

The total RNA was extracted from cells or tumor tissues using TRIZOL reagent (TaKaRa). A pool of cDNA was synthesized from $1 \mu \mathrm{g}$ of RNA with M-MLV reverse transcriptase (Takara Co., Otsu, Japan) as described [17]. Realtime PCR was performed using SYBR Premix Ex Taq (TaKaRa). The following parameters were used for the PCR: $95^{\circ} \mathrm{C}$ for $10 \mathrm{~min}$ followed by 40 cycles at $95^{\circ} \mathrm{C}$ for $30 \mathrm{~s}, 55^{\circ} \mathrm{C}$ for $30 \mathrm{~s}$, and $72{ }^{\circ} \mathrm{C}$ for $45 \mathrm{~s}$. Gene expression was normalized against $18 \mathrm{~S}$ RNA. The primers used in this study are listed in Supplementary Table 1.

\section{Immunofluorescence analysis}

SW1736 and K18 ATC cancer cells were fixed with 4\% paraformaldehyde for $15 \mathrm{~min}$ and permeabilized with $0.01 \%$ Triton X-100 for 15 min. After blocking with $1 \%$ bovine serum in PBS for $30 \mathrm{~min}$, cells were incubated with one of the following antibodies: NIS, Pax8, Smad7, Smad3, and Smad4 (Abcam) diluted in PBS overnight at $4{ }^{\circ} \mathrm{C}$. Then, cells were washed with PBS three times followed by incubation with 1:500 Alexa Fluor 550 and Alexa Fluor 488 phalloidin-conjugated secondary antibodies (Invitrogen) for $1 \mathrm{~h}$. Cells were stained with DAPI for $1 \mathrm{~min}$. Finally, cells were mounted on glass slides in the AquaPoly/Mount medium (Polysciences). Photomicrographs were recorded by an Olympus microscope. The percentage of positive cells was determined after counting at least 300 cells in a double-blinded manner.

\section{HE staining and immunohistochemical analysis}

Human ATC samples were fixed in $4 \%$ paraformaldehyde, dehydrated with ethanol, and then fixed in paraffin. Approximately $4-\mu m$-thick sections were cut and deparaffinized, rehydrated, and stained with hematoxylin-eosin (H\&E). Stained slides were then evaluated using IX81 microscopy (Olympus, Tokyo, Japan).

Immunohistochemical analysis was performed with streptavidin-biotin complex $(\mathrm{ABC})$ approach following the instruction by a Neobioscience kit (Shenzhen, China). Primary antibodies were diluted in PBS as follows: anti-REG $\gamma$, antiNIS, anti-SMAD7, and anti-Pax8. Prior to antibody incubation, an antigen was retrieved in $10 \mathrm{mM}$ sodium citrate, $\mathrm{pH} 6.0$, for $15 \mathrm{~min}$ at $100^{\circ} \mathrm{C}$ in a water bath. Color reaction was visualized after addition of diaminobenzidine (DAB) $-\mathrm{H}_{2} \mathrm{O}_{2}$ as a substrate for peroxidase. All sections were counterstained with hematoxylin, dehydrated, mounted, and observed under a microscope. Staining percentage was classified as negative $(0-25 \%)$, weak $(25-50 \%)$, moderate $(50-75 \%)$, or strong $(75-100 \%)$ according to previous publication [20].

\section{Xenograft mouse models}

ATC cells $\left(5 \times 10^{6}\right.$ in $0.1 \mathrm{~mL}$ of PBS per mouse) were inoculated subcutaneously on the right back sides of the mice. In all, $100 \mu \mathrm{l}$ of luciferase substrate at the concentration of $33 \mathrm{mg} / \mathrm{ml}$ was injected into the intraperitoneal cavity, $\sim 5 \mathrm{~min}$ before imaging. Mice were anesthetized with isoflurane and then ventral images were collected for $30 \mathrm{~s}$ to $2 \mathrm{~min}$ using the IVIS (Xenogen Corp., Alameda, CA). Photons emitted from the primary tumor and lung region were quantified using Living Image software (Xenogen Corp., Alameda, CA).

\section{${ }^{131}$ I uptake and therapy of xenograft tumors in nude mice}

Two-month-old BALB/c nude mice were used in xenograft and radiotherapy studies following the ethical and safety guideline approved by the Animal Center at Jiangsu Institute of Nuclear Medicine.

SW1736 and K18 (ShN and ShR) ATC cells with a stably integrated luciferase reporter gene (effluc) were subcutaneously implanted into the dorsal sides ( $\mathrm{ShN}$ to left and ShR to the right side) of BALB/c nude mice in two groups (six mice in each group). For transplanted tumors sized $6-8 \mathrm{~mm}$ in diameter, Cherenkov imaging 

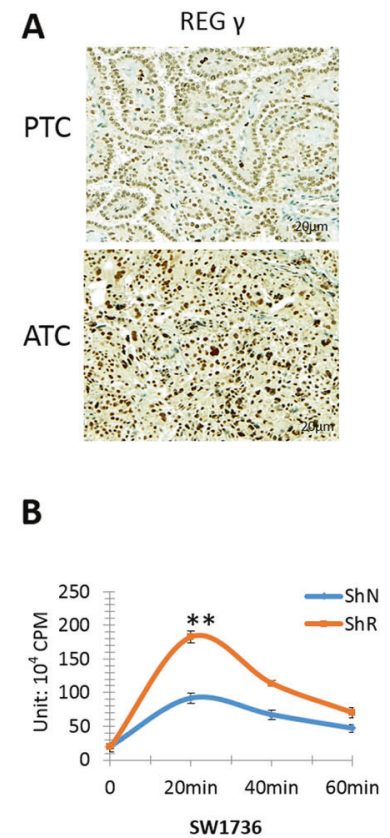

C

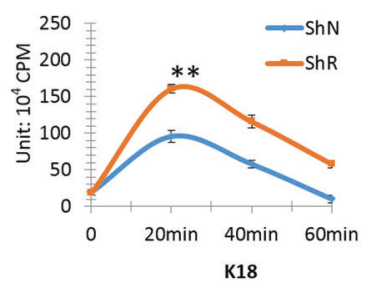

Fig. 1 REG $\gamma$ deficiency augments radioiodine uptake in human ATC cells. a REG $\gamma$ expression was markedly higher in human ATC tissues than PTC tissues. IHC immunostaining (left) and quantitative analyses (right) of REG $\gamma$ expression were performed in 10 ATC and 19 PTC patients. Scale bar, $20 \mu \mathrm{m}$. b, c Time course of ${ }^{131}$ I uptake in ShN and ShR SW1736 (b) and K18 (c) cells. Values represented the results of three independent experiments, and were expressed as mean \pm SEM. $* * p<0.01$, ShR vs. ShN. d, e Xenograft tumors generated from ShR cells had expedited absorption of radioiodine than tumors from ShN cells. Images of tumors from ShR and ShN SW1736-luc (d, $n=28)$ or

was performed for $30 \mathrm{~min}$ after $\mathrm{Na}^{131} \mathrm{I}(0.5 \mathrm{mCi})$ i.p. injection.

For ${ }^{131} \mathrm{I}$ therapy, mice were administered $1.5 \mathrm{mCi} \mathrm{Na}{ }^{131} \mathrm{I}$ by a single i.p. injection. The control mice were administered $0.9 \% \mathrm{NaI}$. Tumors were measured before administration of radioiodine and weekly thereafter. Tumor optical images were acquired by the IVIS imaging system, and tumor size was quantified with Living Image software.

\section{Bioinformatics analysis}

The samples of ATC $(n=20)$ and PTC $(n=17)$ were chosen from the NCBI Gene Expression Omnibus (http://www.ncbi.nlm.nih.gov/geo) to determine the transcript levels of REG $\gamma, N I S, P a x 8$, and Smad7, the accession number is GSE76039.

\section{ATC patient samples}

Ten unnamed human ATC samples were collected from the Second Chengdu Municipal Hospital in China. Patient organization and case access are in agreement with the ethical guidelines and requirements by the hospital.
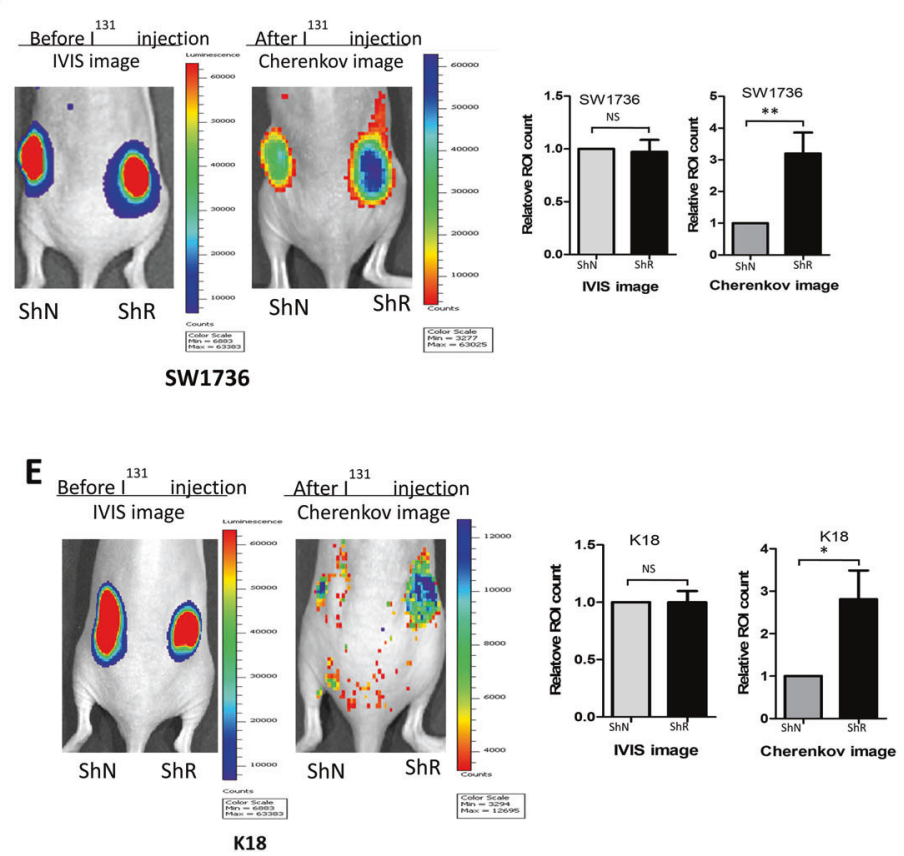

K18-luc cells (e, $n=24)$ on the left represent bioluminescence of luciferase activities, reflecting the tumor size of implantation of tumors upon injection. The images of iodine uptake on the right panels were taken by a cherenkov camera $30 \mathrm{~min}$ after ${ }^{131} \mathrm{I}$ intraperitoneal injection. Luminescence signal intensity was quantified by a region of interest (ROI) analysis and expressed as photons per second per $\mathrm{cm}^{2}$ from mice. The statistical analysis for IVIS ROI values (left) and cherenkov ROI vuales (right) were presented in graphical form. The data were represented as the mean \pm SEM. $* p<0.05, * * p<0.01$, ShR vs. ShN

\section{Statistical analysis}

All experiments were performed independently at least three times. All data were expressed as the mean \pm SD. Paired Student's $t$ test or one-way ANOVA were used to compare the differences in the data between two groups or more. $P$ value of less than 0.05 were considered to be of significance.

\section{Results}

\section{REGY deficiency augments ${ }^{131}$ I uptake in ATC cells}

Previous studies [21] reported anomalous REG $\gamma$ expression in thyroid neoplasms, with higher levels in poorly differentiated than in well-differentiated thyroid cancers. To investigate REG $\gamma$ function in ATC, we analyzed histobiochemistry in ten samples by comparison with papillary thyroid cancer (PTC). REG $\gamma$ displayed nuclear localization in the ATC and PTC tissues. Critically, REG $\gamma$ expression in ATC was found higher than in PTC (Fig. 1a), suggesting that REG $\gamma$ may play a role in the development of poorly differentiated ATC. Therefore, we addressed whether 
A

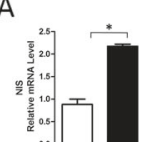

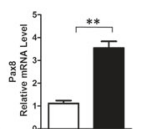

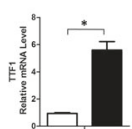
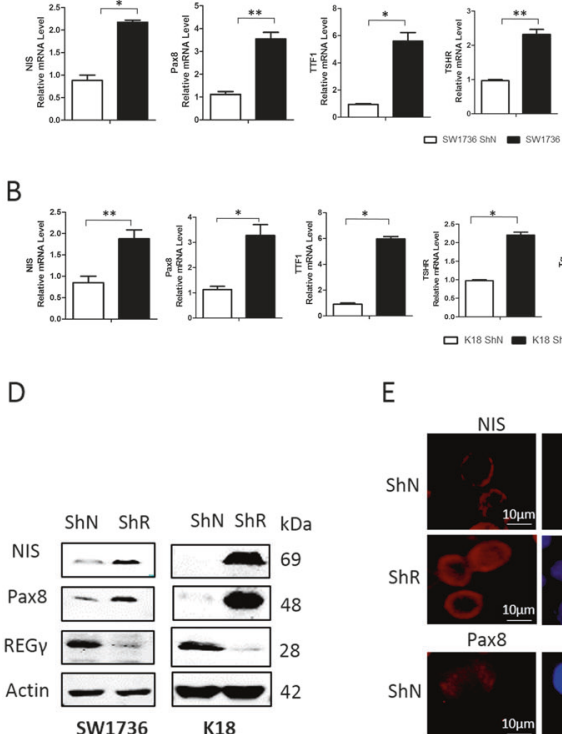

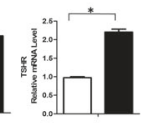

$E$
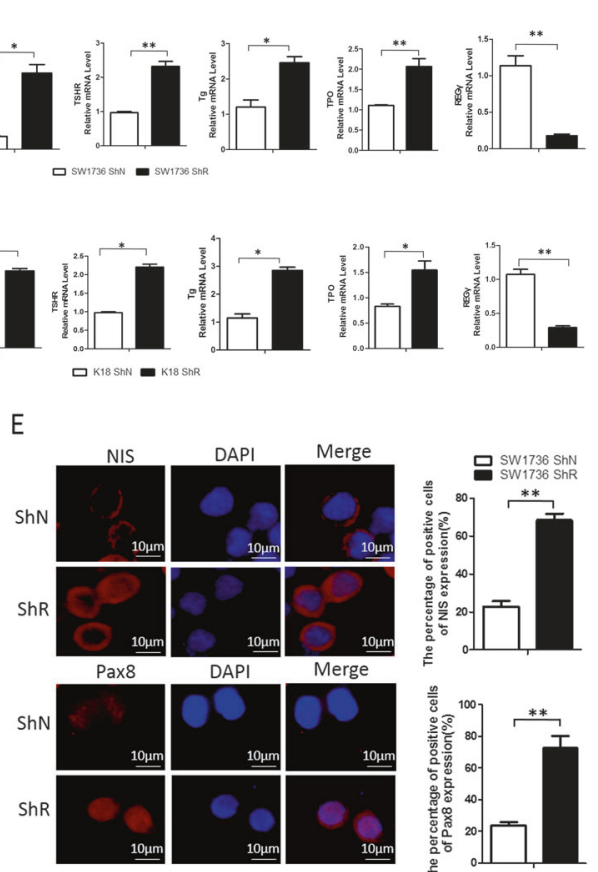

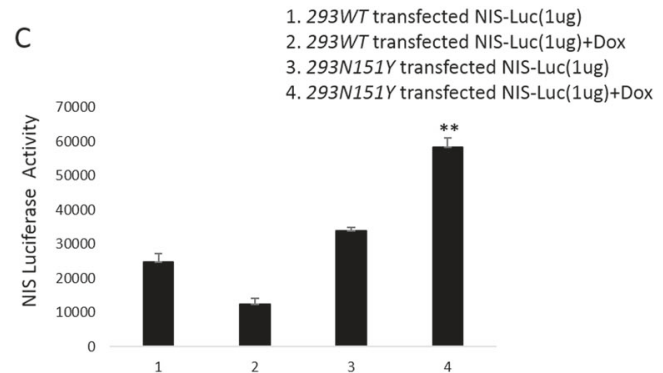

F
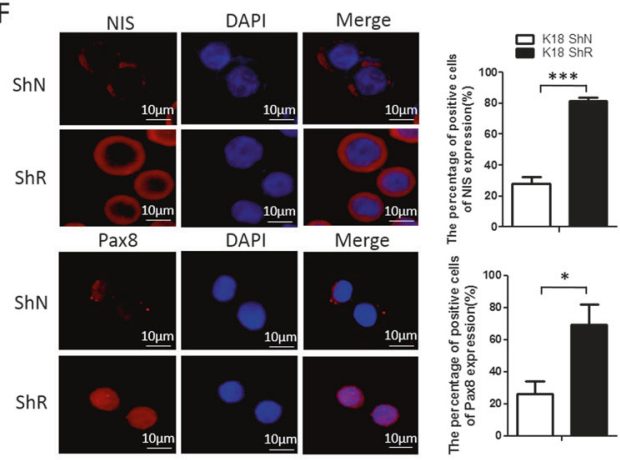

Fig. 2 Abrogation of REG $\gamma$ restores expression of thyroid-specific genes in ATC cells. a Cells with REG $\gamma$ stable knockdown (ShR) had increased expression of NIS, Pax8,TSHR, TTF1, Tg, and TPO when compared with ShN cells. Real-time PCR analyses were performed in SW1736 ShR and control (ShN) ATC cells and expressed as the relative mRNA levles between ShR and ShN cells. b Expression of thyroid-specific genes was analyzed by real-time PCR in ShN and ShR K18 ATC cells. c Inactivation of REG $\gamma$ elevates NIS transcription. NIS-Luc reporter assays were performed in HEK293 cells inducibly

expressing wild-type (WT) or a dominant-negative mutant REG $\gamma$ in the presence or absence of $1 \mu \mathrm{g} / \mathrm{ml}$ doxycycline for $36 \mathrm{~h}$. d Silencing REG $\gamma$ increased NIS and Pax8 protein levels in SW1736 and K18 ShR cells. e, f Immunofluorescence analysis of Pax8 and NIS in SW1736 (e) and K18 (f) ATC cells before and after REG $\gamma$ depletion. The right panels were the quantitative results of Pax8- and NIS-positive cells. A minimum of 300 cells per sample were counted in triplicate. The data were represented as the mean \pm SEM of three independent experiments. $* p<0.05, * * p<0.01, * * * p<0.001$, ShR vs. ShN

hyperactivation of REG $\gamma$ might be involved in the dedifferentiation of ATC.

First, we determined if attenuation of REG $\gamma$ in ATC cells may restore radioiodine uptake. Approximately $20 \mathrm{~min}$ after ${ }^{131}$ I treatment, REG $\gamma$-depleted SW1736-ShR and K18-ShR cells had $94.7 \%$ and $84.2 \%$ higher radioiodine absorption, respectively, than the $\mathrm{ShN}$ control cells (Fig. 1b, c). Then, to substantiate the influence of REG $\gamma$ on iodine intake, we generated xenograft tumors with similar volume and monitored radioiodine absorption in vivo (Fig. 1d, e). Compared with the ShN controls, REG $\gamma$ knockdown greatly enhanced the uptake of iodine in the xenograft tumors, with an increase by 3.2- and 2.8-fold for SW1736-ShR and K18ShR tumors, respectively (Fig. 1d, e). The results suggest the possibility that REG $\gamma$ may be involved in dedifferentiation of ATC cells.

\section{Ablation of REGy restores expression of thyroid-specific genes in ATC cells}

To further determine if REG $\gamma$ regulates dedifferentiation of ATC cells, we evaluated expression of thyroid-specific genes following RNAi of REG $\gamma$. In contrast to the control in ShN

cells, expression of TTF1, Pax8, NIS, Tg, TSHR, and TPO in SW1736-ShR and K18-ShR was markedly upregulated (Fig. 2a, b). The effects of REG $\gamma$ on NIS transcription were also investigated using a NIS luciferase (luc) reporter construct in a Doxycycline-inducible cellular system to overexpress either a wild-type (WT) REG $\gamma$ or a dominant-negative loss-of-function mutant REG $\gamma$ (N151Y). Overexpression of REG $\gamma$ greatly inhibited NIS-luc reporter activity, while the N151Y-mutant failed to do so (Fig. 2c; Supplementary Fig. 1A).

Western blot analysis validated the increase in NIS and Pax8 protein expression in SW1736 and K18 ATC cells, with stable knockdown of REG $\gamma$ (Fig. 2d). Furthermore, immunofluorescent analyses displayed more intensive staining of NIS and Pax8 in ATC-ShR cells than in ATC-ShN cells (Fig. 2e, f). Together, our results indicate that blockade of REG $\gamma$ action has the potential to induce re-differentiation of ATC cells, as demonstrated by restoration of NIS transcription.

\section{REGy suppresses thyroid-specific genes by promoting the TGF- $\beta / S m a d$ signal pathway}

To address the molecular mechanism by which REG $\gamma$ negatively regulates thyroid-specific genes, we performed a 
A

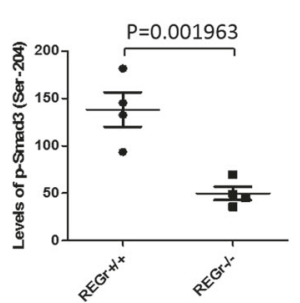

B $\quad \operatorname{ShN} \operatorname{ShR} \operatorname{ShN} \operatorname{ShR} \quad k D a$

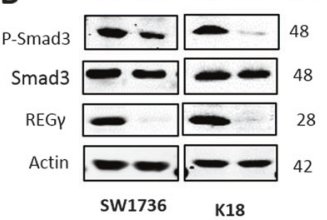

D

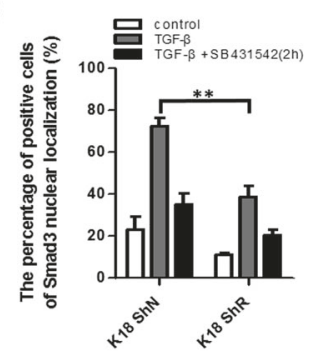

C

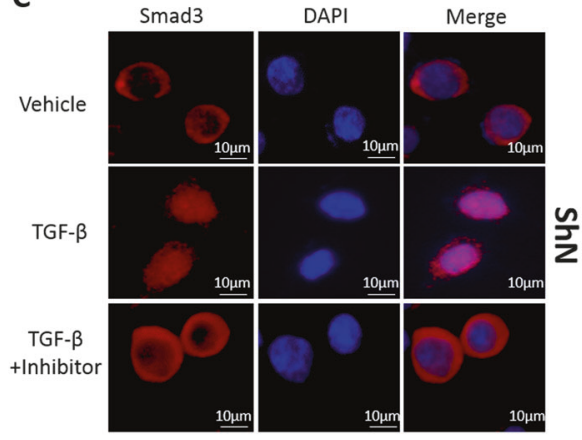

Vehicle
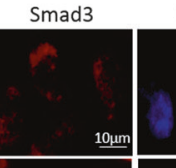

DAPI

TGF- $\beta$

TGF- $\beta$

+ Inhibitor
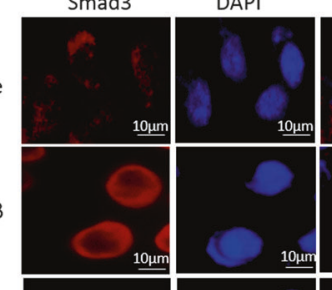
Merge

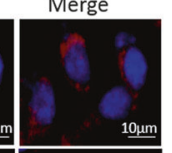

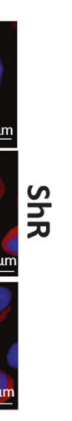
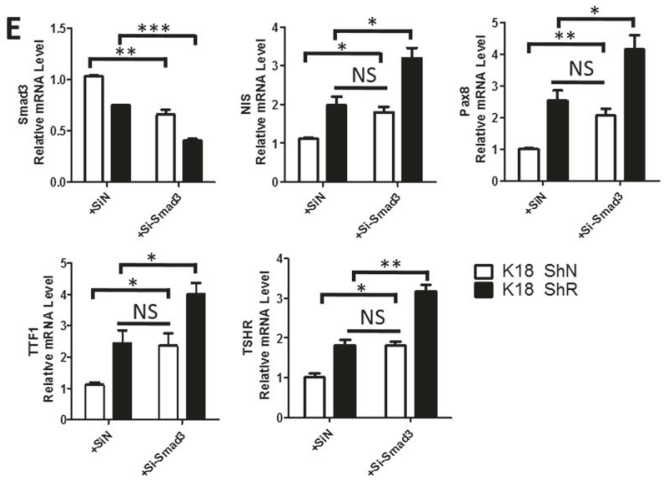

믄 $\mathrm{K} 18$ ShN
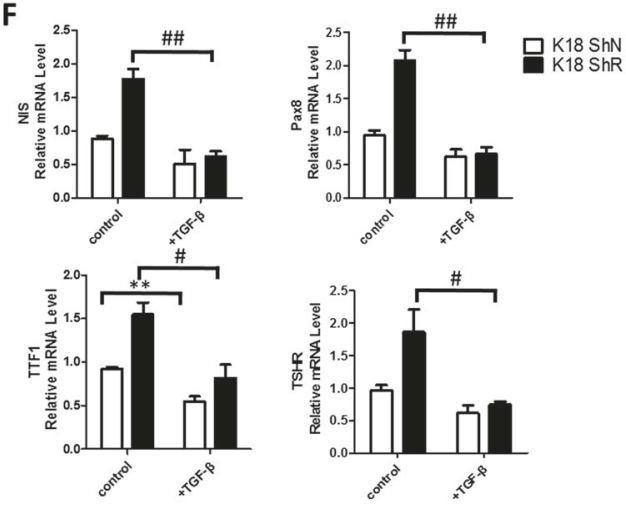

Fig. 3 REG $\gamma$ suppresses thyroid-specific genes by promoting the TGF$\beta /$ Smad signal pathway. a Antibody array analysis disclosed about threefold higher levels of p-Smad3 (ser204) in REG $\gamma$ WT cells than in REG $\gamma$-deficient MEF cells. b The amount of $\mathrm{p}$-Smad3 protein expression was compared between ShN and ShR SW1736 and K18 ATC cells after $5 \mathrm{ng} / \mathrm{ml}$ TGF- $\beta$ for $2 \mathrm{~h}$ by western blotting analysis. c Immunofluorescent staining of Smad3 in K18 ShN and ShR cells before (serum starved for $24 \mathrm{~h}$ ) and after TGF- $\beta(5 \mathrm{ng} / \mathrm{ml}$ for $6 \mathrm{~h})$ in the presence or absence of $10 \mu \mathrm{M}$ TGF- $\beta$ receptor inhibitor SB431542. Nuclei were stained with DAPI. Scale bar, $10 \mu \mathrm{m}$. d The quantitative results for Fig. 3c. The data were represented as the mean \pm SEM of three independent experiments. $* * p<0.01$, ShR vs. ShN. e Silencing Smad3 in K18 ShN ATC cells increased the expression of NIS, Pax8,

high-throughput proteomic screen of REG $\gamma$ targets or effectors by antibody array analysis (FullMoon BioSystem) [15]. Among the top ten proteins differentially expressed in REG $\gamma$ WT and REG $\gamma$ KO MEFs, we found approximately threefold higher levels of active Smad3 (phosphor-Ser 204) [22] in WT than in KO cells (Fig. 3a). We performed western blot analysis to confirm the correlation between REG $\gamma$ and p-Smad3 in ATC cells. Consistently, the pSmad3 levels were markedly higher in ShN SW1736 and K18 ATC cells than in ShR cells (Fig. 3b). Moreover, we validated that nuclear Smad3 is much more abundant in REG $\gamma$ containing ShN than in REG $\gamma$-silenced ShR ATC cells following TGF- $\beta$ treatments (Fig. 3c, d; Supplementary Fig. 1B-C). In contrast, SB-431542, an inhibitor of the TGF- $\beta$ type I receptor, abolished nuclear accumulation of Smad3 in all the cells (Fig. 3c, d; Supplementary Fig. 1BC), reminiscent of REG $\gamma$ ablation. Silencing Smad3
$T S H R$, and TTF1 to levels equivalent to the untreated ShR cells. Cells were transfected with siRNA against $\mathrm{Smad} 3$ for $48 \mathrm{~h}$, and the expression of NIS, Pax8, TSHR, and TTF1 were detected with realtime PCR. The data were represented as the mean \pm SEM of three independent experiments. $* p<0.05, * * p<0.01$, $* * * p<0.001$, siS$\operatorname{mad} 3$ vs. control. f TGF- $\beta$ treatments inhibited thyroid-specific gene expression in K18 ShN and ShR ATC cells. Cells were serum starved for $24 \mathrm{~h}$, then treated with or without $5 \mathrm{ng} / \mathrm{ml}$ TGF- $\beta$ for $6 \mathrm{~h}$. The mRNA expression of NIS, Pax8,TSHR, and TTF1 was detected by real-time PCR. The data were represented as the mean \pm SEM of three independent experiments. $N=3, p<0.05$. ${ }^{*}=$ TGF- $\beta$ compared with ShN Control, ${ }^{\#}=$ TGF- $\beta$ compared with ShR Control

markedly increased the expression of NIS, Pax8,TTF1, and TSHR in K18 and SW1736 ATC cells (Fig. 3e; Supplementary Fig. 1D), consistent with a previous report that TGF- $\beta / S$ mad 3 signaling is a potent repressor of Pax $8 / N I S$ in normal epithelial thyroid cells [8]. To substantiate the role of Smads on NIS expression, NIS luciferase reporter assays were performed in the presence of Smad2 or Smad3. Either greatly inhibited the activitiy of the NIS reporter in SW1736 or K18 ATC cells (Supplementary Fig. 1E).

Indeed, TGF- $\beta$ signal transduction is crippled in ShR cells since we found de-repression of thyroid-specific genes (NIS, Pax8, TTF1, and TSHR) in both K18 and SW1736 ShR cells compared with ShN ATCs (Fig. 3f; Supplementary Fig. 2A), suggesting that REG $\gamma$ might be a critical regulator of the TGF- $\beta$ signal pathway. Consistently, expression of classical TGF- $\beta$ target genes, including PAI- 1 and $C T G F$, was markedly higher in SW1736 and K18 ShN 
A

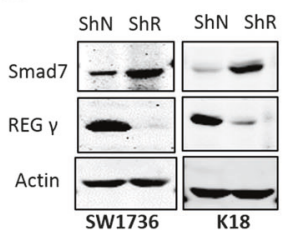

B
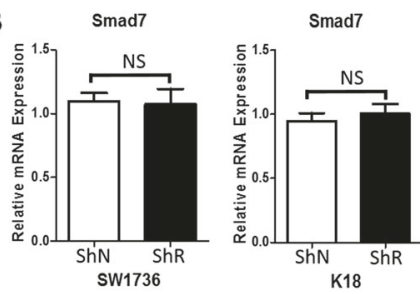

D

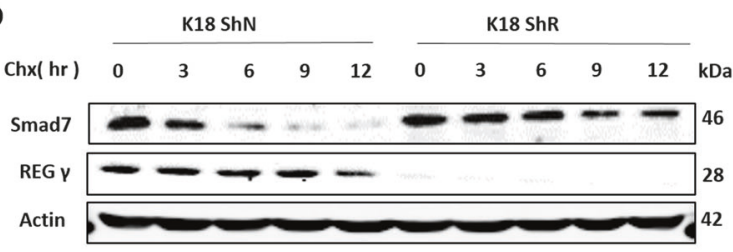

E

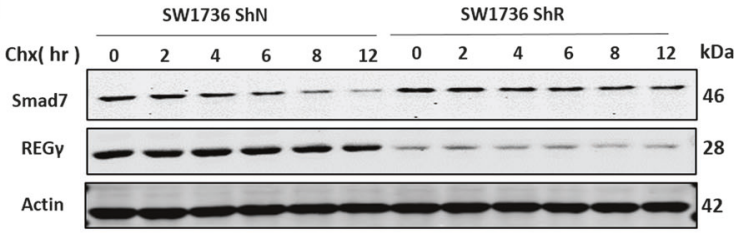

Fig. 4 REG $\gamma$ promotes the degradation of Smad7. a REG $\gamma$ knockdown increased the protein expression of Smad7 by western blot analysis in SW1736 and K18 ShN and ShR ATC cells. b The mRNA expression of Smad7 was similar between ShR and ShN ATC cells by real-time PCR analysis. c Immunofluorescence analysis showed stronger staining of Smad7 in K18 ATC cells with knockdown of REG $\gamma$. The numbers of Smad7-positive cell number were quantitated. The data were represented as the mean \pm SEM. $* * p<0.01$, ShR vs. ShN. d, e REG $\gamma$ regulated Smad7 stability. K18 (d) and SW1736 (e) ShN and ShR cells were serum starved for $24 \mathrm{~h}$, treated with $5 \mathrm{ng} / \mathrm{ml}$ TGF- $\beta$ for $6 \mathrm{~h}$ before the addition of cycloheximide $(100 \mu \mathrm{g} / \mathrm{ml})$ for indicated time

than in ShR cells after TGF- $\beta$ treatments (Supplementary Fig. 2B, C). In contrast, NIS and Pax8 expression, negatively regulated by REG $\gamma$, displayed a marked decrease in a time-dependent manner following the TGF- $\beta$ activation in ShN cells, while maintained higher levels in ShR cells (Supplementary Fig. 2D, E). The percentage of nuclear Smad3/Smad4 positive cells was significantly decreased with REG $\gamma$ knockdown (Supplementary Fig. 3A, B). These data indicate that REG $\gamma$ positively regulates the activity of the TGF- $\beta /$ Smad signal pathway in ATC cells. Thus, restoration of thyroid-specific gene expression in REG $\gamma$ silenced ATC cells may depend on the inhibition of the TGF- $\beta /$ Smad signal pathway.

\section{REGy negatively regulates Smad7 by directly promoting its degradation}

Although Smad3 is a key effector regulated by REG $\gamma$, it is not a direct target of the REG $\gamma$ proteasome. By searching for negative regulators of the TGF- $\beta$ pathway, we observed striking accumulation of Smad7 protein (Fig. 4a), but no increase in
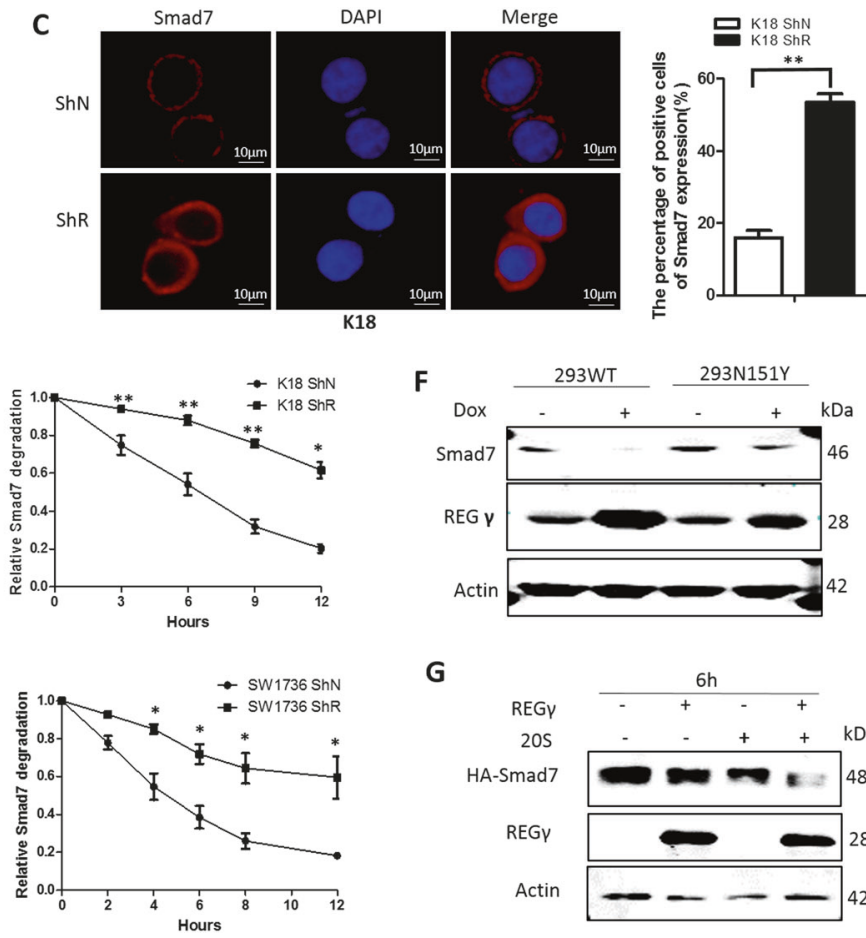

$\mathbf{G}$

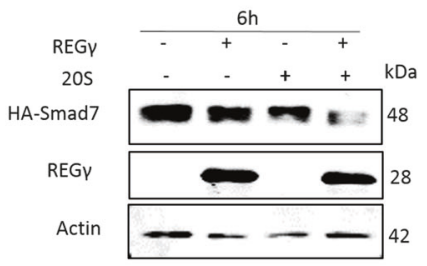

and harvested for western blotting analysis. The quantitative results of Smad7 stability were plotted to indicate dynamic changes (two-tailed Student's $t$ test, $n=3)$. ${ }^{*} p<0.05$, ** $p<0.01$, *** $p<0.001$, ShR vs. ShN. f Induced expression of wild-type (WT), but not inactive mutant N151Y REG $\gamma$ promotes the degradation of Smad7 in HEK293 cells. REG $\gamma$ or a mutant form of REG $\gamma$ was induced in HEK293 cells treated with $1 \mu \mathrm{g} / \mathrm{ml}$ of doxycycline for $48 \mathrm{~h}$ and followed by western blot analysis. $\mathbf{g}$ REG $\gamma$ directly promoted the degradation of Smad7. In vitro proteolytic analyses were performed using purified REG $\gamma, 20 \mathrm{~S}$ proteasome, and $\mathrm{Smad} 7$ protein at $30^{\circ} \mathrm{C}$ for $6 \mathrm{~h}$

mRNA expression (Fig. 4b) in ATC cells with stable RNAi depletion of REG $\gamma$. Increased expression of Smad7 in REG $\gamma$ deficient K18 and SW1736 cells was validated by immunofluorescence (Fig. 4c; Supplementary Fig. 4A). The percentage of Smad7-positive cells was about threefold higher in both REG $\gamma$-ShR K18 and SW1736 cells than in the corresponding ShN cells (Fig. 4c; Supplementary Fig. 4A). These results support the concept that REG $\gamma$ negatively regulates the protein levels of Smad7 in ATC cells.

To determine if REG $\gamma$ mediates Smad7 degradation, we analyzed the dynamics of Smad7 stability in the presence of cycloheximide, a protein synthesis inhibitor. In ATC cells lacking REG $\gamma$, Smad7 protein is much more stable with a significantly slower decay rate than in the REG $\gamma$ WT control cells (Fig. 4d, e), suggesting that REG $\gamma$ is required for degradation of Smad7 in these cells. We carried out gain-of-function experiments using the doxycycline-inducible 293 cells system [10] to overexpress either WT REG $\gamma$ or the REG $\gamma-\mathrm{N} 151 \mathrm{Y}$ mutant. Induction of REG $\gamma$ triggered degradation of Smad7 (Fig. 4f), whereas induced expression of the REG $\gamma-\mathrm{N} 151 \mathrm{Y}$ mutant failed to do so (Fig. 4f). We validated physical 
interactions between REG $\gamma$ and Smad7 in cells by reciprocal coimmunoprecipitation experiments (Supplementary Fig. 4B, C). To determine if the Smad7 is a direct target of the REG $\gamma$ proteasome, we performed cell-free proteolysis with purified proteins. Incubation of in vitro-translated $\mathrm{Smad} 7$ with $20 \mathrm{~S}$ proteasome alone or REG $\gamma$ alone exhibited no significant degradation of Smad7, but a combination of REG $\gamma$ and 20S proteasome promoted rapid turnover of $\operatorname{Smad} 7$ (Fig. $4 \mathrm{~g}$ ). Taken together, our results demonstrate that REG $\gamma$ can directly interact with Smad7 and promote its degradation in vitro and in SW1736 or K18 ATC cells.

\section{Clinical relevance of REGy/Smad7-dependent regulation of thyroid-specific genes in ATC}

To substantiate that REG $\gamma$-mediated regulation of thyroidspecific genes is Smad7 dependent, we performed loss- and gain-of-function experiments in ATC cells. Depletion of Smad7 by RNAi markedly downregulated the expression of NIS, Pax8, TTF1, Tg, and TSHR, which is more dramatic in REG $\gamma$-defective ShR than in ShN K18 and SW1736 cells (Fig. 5a; Supplementary Fig. 4D). Depletion of Smad7 eliminated the differences in thyroid-specific gene expression between ShR and ShN ATC cells, suggesting that REG $\gamma$ action relies on Smad7. In contrast, stable overexpression of Smad7 upregulated the expression of NIS, $P a x 8, T T F 1, T g$, and $T S H R$, with a greater increase in REG $\gamma$ ShN cells than in REG $\gamma$ ShR K18 or SW1736 ATC cells (Fig. 5b; Supplementary Fig. 4E). Interestingly, overexpression of Smad7 recovered thyroid-specific gene transcription in ShN cells to levels equivalent to those in control ShR cells (Fig. 5b; Supplementary Fig. 4E). These results demonstrate that Smad7 mediates REG $\gamma$-dependent regulation of thyroid-specific gene expression in ATC cells.

To understand the clinical significance of the REG $\gamma$ pathway in ATC, we performed bioinformatics analyses using the NCBI Gene Expression Omnibus database to compare transcription levels of $R E G \gamma, N I S, \operatorname{Pax} 8$, and Smad7 in human ATC and PTC samples. Indeed, transcription levels of $R E G \gamma$ are higher $(P<0.001)$ in ATC than that in PTC, while NIS and Pax8 were lower in ATC than PTC (Fig. 5c), representing an inverse correlation between REG $\gamma$ and NIS/Pax8 in human ATC samples. However, Smad7 mRNA levels showed no significant difference between ATC and PTC (Supplementary Fig. 5A), suggesting a posttranscriptional regulation. Next, we evaluated the protein levels of REG $\gamma$, NIS, Pax8, and Smad7 in the human ATC samples by immunohistochemistry comparison with normal thyroid tissues. There was very weak staining of REG $\gamma$ accompanied with dramatically higher NIS, Pax8, and Smad7 expression in normal human thyroid tissues (Fig. 5d). On the contrary, the REG $\gamma$ in ATC was significantly elevated, associated with drastically reduced expression of NIS, Pax8, and Smad7 (Fig. 5d). Quantified analysis of the IHC data supports that REG $\gamma$ expression is negatively correlated with NIS, Pax8, and Smad7 protein levels in human ATC (Fig. 5d), implicating REG $\gamma$-Smad7 regulation in ATC tissues.

\section{REGy abrogation accentuates ${ }^{131}$ I therapeutic sensitivity to xenograft ATC tumors}

Given REG $\gamma$-dependent regulation of NIS and radioiodine uptake, we evaluated if the therapeutic effect of ${ }^{131}$ I can be modified in an ATC cell xenograft model with altered REG $\gamma$ expression. Since REG $\gamma-\mathrm{KO}$ tumors grow slower $[18,20]$, a cohort of ShN and ShR ATC cells were inoculated individually at different time point so that both tumor types would reach $6-8 \mathrm{~mm}$ in diameter simultaneously. Following transplantation of paired $\mathrm{ShN}$ and ShR ATC tumors to animals, Cherenkov imaging analysis with $\mathrm{Na}^{131} \mathrm{I}$ ensured absorption of radioiodine (Fig. 1d, e). Dynamic evaluation of tumor regression by luciferase activities showed greater decrease in SW1736 ShR than in ShN tumors at days 14 and 21 post therapy (Fig. 6a). Similar results were observed for K18 tumors with a marked reduction of bioluminescence signals in the ShR tumors compared with ShN tumors at days 14 and 21 (Fig. 6b). At the final day of ${ }^{131}$ I treatments, we harvested and measured actual sizes of the paired tumors. Noticeably, immunostaining showed that Pax8, NIS, and Smad7 were still significantly higher in REG $\gamma$-deleted tumors than $\mathrm{ShN}$ tumors (Supplementary Figs 5B, C). The volume of tumors derived from SW1736 and K18 ShR cells had greater reduction than the tumors from ShN control cells with an approximately threefold difference in tumor volumes on average (Fig. 6c-f; Supplementary Fig. 6A, B). Since the tumor promoting effect of REG $\gamma$-positive ShN cells yielded 1.5fold higher growth rate benefit over ShR cells, we subtracted the growth differences between ${ }^{131}$ I-treated vs. untreated groups to evaluate the net effect of radiotherapy. The results disclosed a greater growth inhibition in treated ShR tumors, indicating more efficient radioiodine therapy in sensitized ShR groups (Fig. 6g, h). Taken together, REG $\gamma$ inhibition could be a promising direction for treating ATC in the future.

\section{Discussion}

In this study, we have demonstrated that REG $\gamma$ is an important factor in the regulation of thyroid-specific genes in ATC by directly targeting Smad7 for proteasomemediated degradation and enhancing the TGF- $\beta$ signal pathway, which negatively regulates thyroid-specific genes. The significance of REG $\gamma$-depletion restoration of ATC 
A

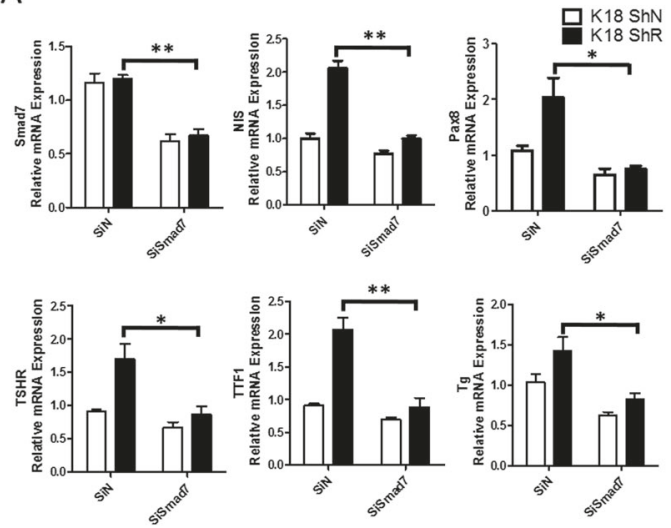

B
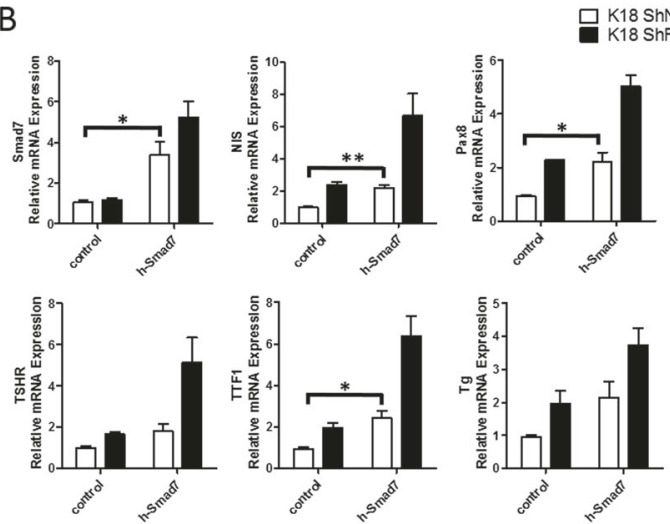

Fig. 5 REG $\gamma$-Smad7 regulation and correlation with expression of thyroid-specific genes in ATC. a Smad7 knockdown blocked the increase of thyroid-specific gene expression induced by REG $\gamma$ deficiency. K18 ShN and ShR cells were transfected with siRNA against Smad7 for $48 \mathrm{~h}$, and the expression of NIS, Pax8, TSHR, Tg, and TTF1 were detected by real-time PCR. The data were represented as the mean \pm SEM. $N=3, * p<0.05, * * p<0.01$, siSmad7 vs. control. b Smad7 overexpression promoted the expression of thyroid-specific genes in REG $\gamma$ ShN K18 ATC cells to levels equivalent to REG $\gamma$ ShR cells. Cells were transfected with plvx and plvx-GFP-Smad7 vector for $48 \mathrm{~h}$, and the expression of NIS, Pax8, TSHR, Tg, and TTF1 were

differentiation is highlighted by increased uptake of radioiodine and improved effects of ${ }^{131} \mathrm{I}$ treatment in the ATC xenograft tumor model. Thus, REG $\gamma$ appears to be important for driving transformation of ATC from pre-existing differentiated thyroid cancer. This study provides molecular basis that targeting a noncanonical proteasome degradation pathway or directly targeting p-Smad3 may be new directions for ATC therapy.

ATC has the most aggressive progression among thyroid malignancies due to its dedifferentiation; however, the molecular mechanisms of ATC are far from understood. Mutations of various pathways, including p53, Braf, Ras, PTEN/PI3K, and Wnt- $\beta$-catenin have been described as potential drivers for ATC [23]. Current therapeutic approaches commonly aim at inhibiting cell proliferation pathways or restoring the function of tumor suppressors.
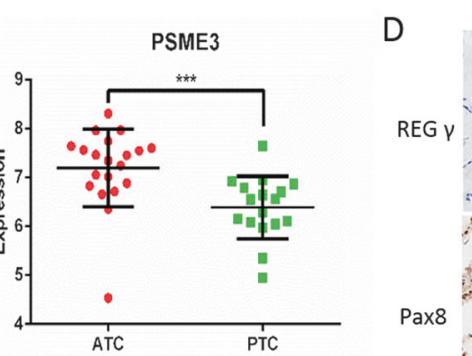

ATC
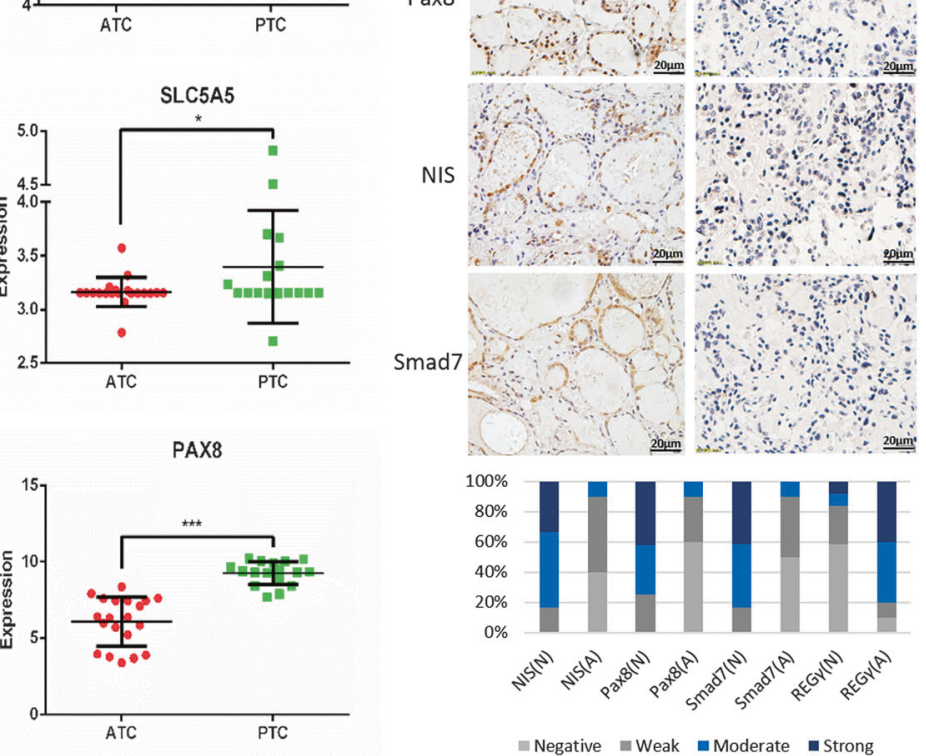

detected by real-time PCR. Overexpression efficiency of Smad7 was confirmed by real-time PCR. The data were represented as the mean \pm SEM. $N=3, * p<0.05$, Smad7 vs. Vector. c The expression of REG $\gamma$, Pax8, and NIS was analyzed using the microarray data (GSE76039) containing 20 ATC and 17 PTC samples. The data were represented as the mean \pm SEM. $* p<0.05, * * * p<0.001$. d The expression of REG $\gamma$, Smad7, Pax8, and NIS as well as the quantitative results of expression profiles in ten human ATC tissues and adjacent normal tissues by immunohistochemistry. Representative images of immunohistochemical staining are shown. Scale bar: $20 \mu \mathrm{m}$. Original magnification $\times 40$

However, single-modality therapy such as Braf inhibitor, PI3K inhibitor, or multimodal treatments has limited effects on ATC, and the mean survival time from diagnosis to death continues to remain at about 6 months [23]. Therefore, there is an urgent need for novel therapies against ATC. Here, we demonstrate for the first time that REG $\gamma$ is a regulator for Pax8 and NIS transcription. We have provided proof-ofprinciple evidence that inhibiting REG $\gamma$ activity greatly improves iodine uptake in ATC cells in vitro and in vivo, which benefits ${ }^{131}$ I therapy in ATC tumor model. Given that REG $\gamma$-mediated Smad7 degradation induces NIS repression, combinational therapy to target REG $\gamma$ and other proteins such as BRAF ${ }^{\mathrm{V} 600 \mathrm{E}}$ might be promising in the future.

It is well established that the TGF- $\beta /$ Smad pathway plays a critical role in ATC progression and metastasis. Indeed, blocking TGF- $\beta 1$ inhibits growth and invasion of ATC cells 


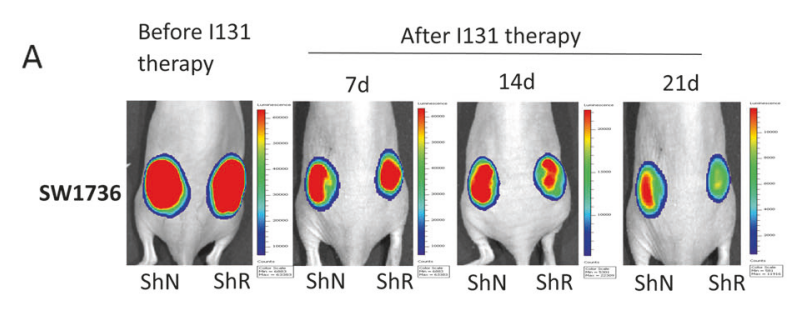

C
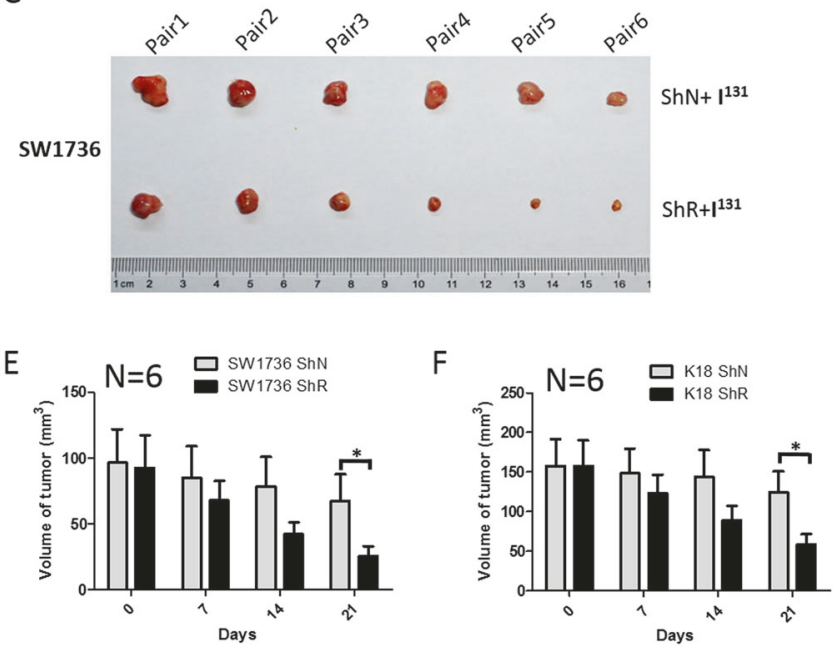

Fig. 6 REG $\gamma$ abrogation sensitizes xenograft ATC tumors to ${ }^{131} \mathrm{I}$ therapy. a, b REG $\gamma$ knockdown (ShR) in SW1736 (a) and K18 (b) cells markedly improved the effects of radioiodine therapy compared with the controls (ShN). Each animal with the same size of xenographt tumors from ShN and ShR cells was injected i.p. with $1.5 \mathrm{mCi}$ of carrier-free $\mathrm{Na}^{131} \mathrm{I}$ in $0.1 \mathrm{-ml}$ normal saline. Representative luciferase/ luciferin bioluminescence images of tumor-xenografted mice were acquired at the indicated days after the injection of radioactive iodine. Rainbow scales were expressed in radiance $\left(\mathrm{p} / \mathrm{s} / \mathrm{cm}^{2} / \mathrm{sr}\right)$.

[7, 24]. ATC malignancy caused by TGF- $\beta$ is probably based on epithelial-to-mesenchymal transition [25, 26]. However, TGF- $\beta$ also acts as an inhibitor of cell proliferation by suppressing function of c-Myc and enhancing expression of CDK inhibitors such as $\mathrm{p} 15^{\mathrm{INK} 4 \mathrm{~B}}, \mathrm{p} 21^{\mathrm{CIP1} 1}$, and $\mathrm{p} 27^{\mathrm{KIP} 1}$ [27], particularly exhibiting tumor suppressive effects in healthy noncancerous cells and in early-stage cancerous cells [28]. Since ATC frequently derives from PTC and can co-exist with PTC, in which the TGF- $\beta$ pathway may function differently than it does in ATC alone. In addition, numerous reports suggest that Smad4 deficiency drives cancer metastasis and tumor malignancy [29-31]. Thus, the function of the TGF- $\beta$ signal pathway is further complicated by Smad-dependent and Smadindependent pathways [32]. Since TGF- $\beta$ exerts both tumor suppressive and a metastasis-promoting functions, use of TGF- $\beta$ receptor inhibitors for ATC patients seems not to be an optimal choice in anticancer therapy.

Smad7 is a key negative regulator of TGF- $\beta$ signaling by binding the $\mathrm{MH} 2$ domain and blocking R-Smad activation
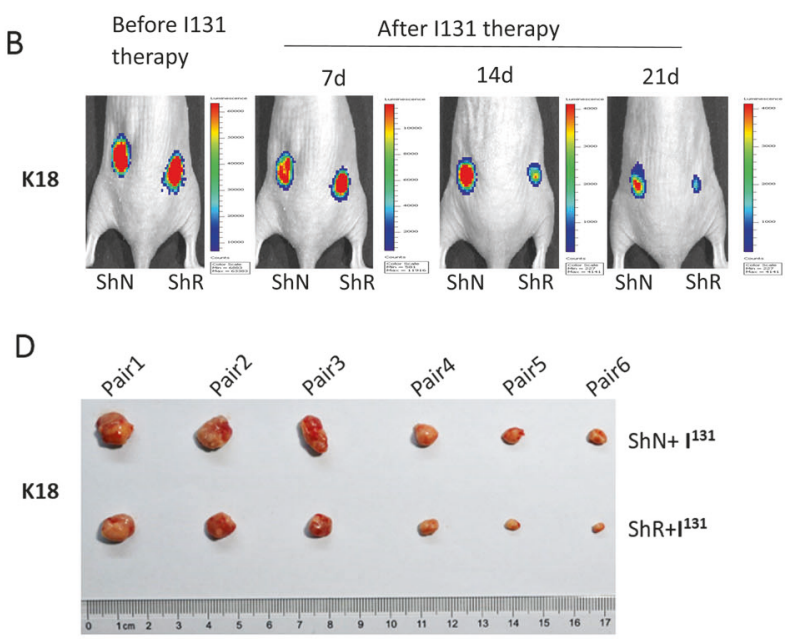

G

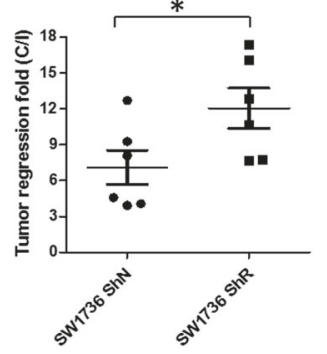

$\mathrm{H}$

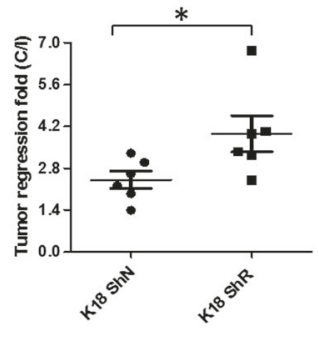

c, d Representative photos of xenographt tumors in nude mice by injecting SW1736 (c) or K18 (d) cells at day 21 after radioiodine therapy. e, $\mathbf{f}$ The tumor volume of $\mathrm{NaI}^{131}$ therapy for $0,7,14$, or 21 days in nude mice was assessed by caliper measurement. The data represented mean \pm SEM. $N=6, * p<0.05$, ShN vs. ShR. g, h Tumor regression fold was calculated after radioiodine therapy. $\mathrm{REG} \gamma^{-1-}$ xenografts showed quicker decrease than $\mathrm{REG} \gamma^{+/+}$ones. The data represented mean \pm SEM. $N=6, * p<0.05, * * p<0.01$, ShN vs. ShR

[33]. The key function of Smad7 is to control activated Smad2/3 and prevent nuclear translocation. In this study, we observed that the upregulation of NIS and Pax8 after siSmad3 was almost similar to the extent induced by REG $\gamma$ knockdown in ATC cells, implying that selective targeting Smad3 may be applicable for restoration of the sensitivity to radioiodine therapy. Considering REG $\gamma$ knockout mice can survive and breed normally, we assume that targeting REG $\gamma$ may be an alternative option for ATC therapy in the future with less side effects than inhibition of the conventional ubiquitin-proteasome degradation system. In addition, Smad7 has TGF- $\beta$-independent function in promoting pluripotency by amplifying STAT3 activation [34]. Thus, our study suggests: (1) targeting Smad7 downstream of TGF- $\beta$ but not directly affecting receptor levels, may be an economical approach. (2) Proteasome inhibition has proven anticancer effects in ATC [35, 36], the narrow-scoped REG $\gamma$ proteasome may be specific. It is also noticeable that REG $\gamma$ was reported to interact with E3-ubiquitin ligase Smurf1 and mediates its degradation [37]. Interestingly, 


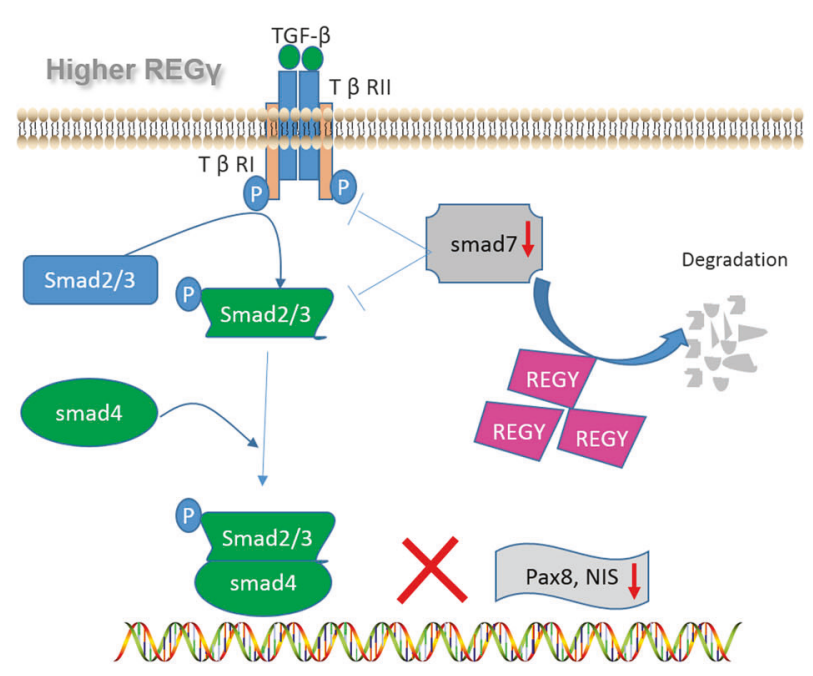

Fig. 7 A Model of REG $\gamma$-dependent regulation in ATC dedifferentiation. In human ATC cells, overexpression of REG $\gamma$ promotes the degradation of Smad7, thus activating TGF- $\beta$ signaling and blocking thyroid-specific gene expression. In contrast, cells with REG $\gamma$

Smad7 also function by binding Smurf2 to T $\beta R I$, controlling its turnover and mitigating TGF- $\beta$ signaling [38]. Given the net effects of Smad7 and Smurf1 on TGF- $\beta /$ Smad signal pathways are consistent, it is likely that Smad7 and Smurfs may contribute together to the activation of TGF- $\beta$ signaling affected by REG $\gamma$ in SW1736 and K18 ATC cells.

Loss of thyroid-specific gene expression, especially NIS, contributes to lack of response to radioiodine ablation therapy in ATC, a reason for the high lethality of ATC patients. WTp53 was shown to upregulate NIS expression [39], while Braf $^{\mathrm{V} 600 \mathrm{E}}$ and HDAC inhibited its transcription $[6,9]$. Coincident with our previous findings [16, 40], abrogation of REG $\gamma$ enhances p53 levels in multiple cell types. Whether REG $\gamma$ may also regulate NIS expression in ATC via the p53 pathway is not clear.

Taken together, our results demonstrate a critical role of REG $\gamma$ in regulating ATC cell differentiation. Antagonizing REG $\gamma$ greatly restores expression of thyroid-specific genes, intensifies iodide uptake and accentuates cellular sensitivity to radioiodine therapy in ATC (Fig. 7). Molecularly, REG $\gamma$ acts by activating TGF- $\beta /$ Smad signaling via proteasomedependent degradation of Smad7 (Fig. 7), adding an additional layer of the regulatory mechanism in a ubiquitinindependent manner. Therefore, this study presents evidences that blocking REG $\gamma$ activity may be an alternative therapeutic strategy for anaplastic thyroid carcinoma.

Acknowledgements We thank Dr. James A. Fagin (Memorial Sloan Kettering Cancer Center) for kindly providing SW1736 cell line. This work was supported by the National Basic Research Program of China (2015CB910402, 2016YFC0902102), the National Natural Science Foundation of China $(31200878,31730017,91629103$, 81471066,

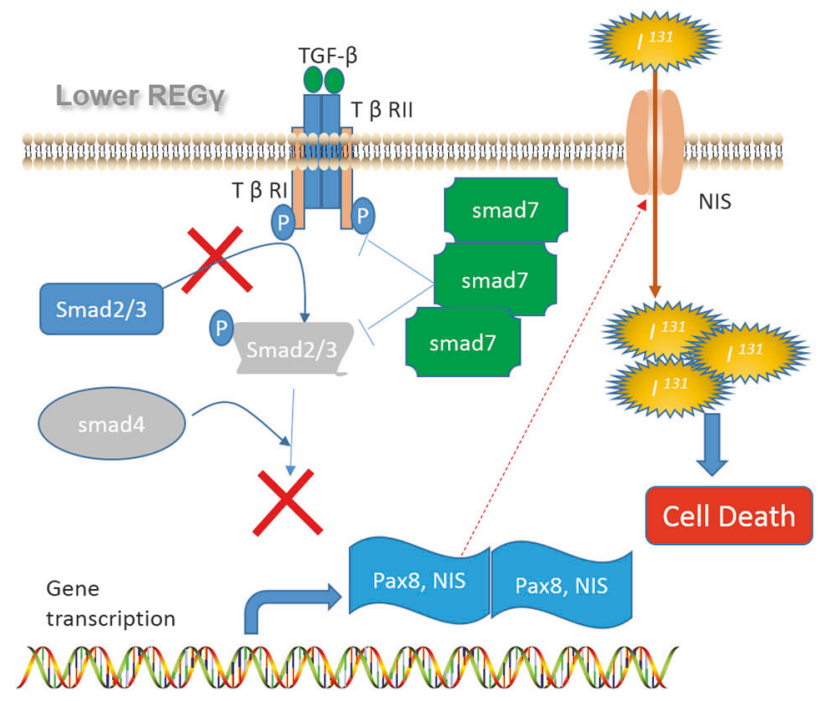

depletion improves Smad7 stability and inhibits Smad2/3 activation, leading to ATC cell re-differentiation and more sensitive responses to radioiodine therapy

31401012, 81672883, 81401837, and 31670882), the Science and Technology Commission of Shanghai Municipality (17ZR1407900, 11ZR1410000, 14430712100, 14ZR1411400, and 16ZR1410000), Shanghai Rising-Star Program (16QA1401500), the applied Basic Research Program of Science and Technology Department of Sichuan Province (2015JY0038). We also thank ECNU Multifunctional Platform for Innovation (011) for keeping and raising mice.

\section{Compliance with ethical standards}

Conflict of interest The authors declare that they have no conflict of interest.

Publisher's note: Springer Nature remains neutral with regard to jurisdictional claims in published maps and institutional affiliations.

Open Access This article is licensed under a Creative Commons Attribution 4.0 International License, which permits use, sharing, adaptation, distribution and reproduction in any medium or format, as long as you give appropriate credit to the original author(s) and the source, provide a link to the Creative Commons license, and indicate if changes were made. The images or other third party material in this article are included in the article's Creative Commons license, unless indicated otherwise in a credit line to the material. If material is not included in the article's Creative Commons license and your intended use is not permitted by statutory regulation or exceeds the permitted use, you will need to obtain permission directly from the copyright holder. To view a copy of this license, visit http://creativecommons. org/licenses/by/4.0/.

\section{References}

1. Onoda N, Sugino K, Higashiyama T, Kammori M, Toda K, Ito K$\mathrm{I}$, et al. The safety and efficacy of weekly paclitaxel administration for anaplastic thyroid cancer patients: a nationwide prospective study. Thyroid. 2016;26:1293-9. 
2. Hsu K-T, Yu X-M, Audhya AW, Jaume JC, Lloyd RV, Miyamoto $\mathrm{S}$, et al. Novel approaches in anaplastic thyroid cancer therapy. Oncologist. 2014;19:1148-55.

3. Links T, Van Tol K, Jager P, Plukker JTM, Piers D, Boezen H, et al. Life expectancy in differentiated thyroid cancer: a novel approach to survival analysis. Endocr Relat Cancer. 2005;12:273-80.

4. Boland A, Ricard M, Opolon P, Bidart J-M, Yeh P, Filetti S, et al. Adenovirus-mediated transfer of the thyroid sodium/iodide symporter gene into tumors for a targeted radiotherapy. Cancer Res. 2000;60:3484-92.

5. Hébrant A, Dom G, Dewaele M, Andry G, Trésallet C, Leteurtre E, et al. mRNA expression in papillary and anaplastic thyroid carcinoma: molecular anatomy of a killing switch. PLoS ONE. 2012; 7:e37807.

6. Ke C-C, Liu R-S, Chi C-W, Lee C-H. HDAC inhibitor induces reexpression of thyroid specific genes as well as differentiating in anaplastic thyroid cancer. J Nucl Med. 2013;54(supplement 2): $1341-1341$.

7. Zhang K, Liu X, Hao F, Dong A, Chen D. Targeting TGF- $\beta 1$ inhibits invasion of anaplastic thyroid carcinoma cell through SMAD2-dependent S100A4-MMP-2/9 signalling. Am J Transl Res. 2016;8:2196.

8. Costamagna E, García B, Santisteban P. The functional interaction between the paired domain transcription factor Pax 8 and Smad3 is involved in transforming growth factor- $\beta$ repression of the sodium/iodide symporter gene. J Biol Chem. 2004;279:3439-46.

9. Riesco-Eizaguirre G, Rodríguez I, De la Vieja A, Costamagna E, Carrasco N, Nistal M, et al. The BRAFV600E oncogene induces transforming growth factor $\beta$ secretion leading to sodium iodide symporter repression and increased malignancy in thyroid cancer. Cancer Res. 2009;69:8317-25.

10. Li X, Amazit L, Long W, Lonard DM, Monaco JJ, O'Malley BW. Ubiquitin-and ATP-independent proteolytic turnover of p21 by the REG $\gamma$-proteasome pathway. Mol Cell. 2007;26:831-42.

11. Li X, Lonard DM, Jung SY, Malovannaya A, Feng Q, Qin J, et al. The SRC-3/AIB1 coactivator is degraded in a ubiquitin-and ATP-independent manner by the REG $\gamma$ proteasome. Cell. 2006;124:381-92.

12. Zhang $Z$, Zhang R. Proteasome activator PA28 $\gamma$ regulates $\mathrm{p} 53$ by enhancing its MDM2-mediated degradation. EMBO J. 2008;27:852-64.

13. Xu J, Zhou L, Ji L, Chen F, Fortmann K, Zhang K, et al. The $\mathrm{REG} \gamma$-proteasome forms a regulatory circuit with $\mathrm{I} \kappa \mathrm{B} \varepsilon$ and $\mathrm{NF \kappa B}$ in experimental colitis. Nat Commun. 2016;7:10761.

14. Liu S, Lai L, Zuo Q, Dai F, Wu L, Wang Y, et al. PKA turnover by the REG $\gamma$-proteasome modulates FoxO1 cellular activity and VEGF-induced angiogenesis. J Mol Cell Cardiol. 2014;72:28-38.

15. Dong S, Jia C, Zhang S, Fan G, Li Y, Shan P, et al. The REG $\gamma$ proteasome regulates hepatic lipid metabolism through inhibition of autophagy. Cell Metab. 2013;18:380-91.

16. Li L, Zhao D, Wei H, Yao L, Dang Y, Amjad A, et al. REG $\gamma$ deficiency promotes premature aging via the casein kinase 1 pathway. Proc Natl Acad Sci. 2013;110:11005-10.

17. He J, Cui L, Zeng Y, Wang G, Zhou P, Yang Y, et al. REG $\gamma$ is associated with multiple oncogenic pathways in human cancers. BMC Cancer. 2012;12:75.

18. Li L, Dang Y, Zhang J, Yan W, Zhai W, Chen H, et al. REG $\gamma$ is critical for skin carcinogenesis by modulating the $\mathrm{Wnt} / \beta$-catenin pathway. Nat Commun. 2015;6:6875.

19. Wang Q, Gao X, Yu T, Yuan L, Dai J, Wang W, et al. REG $\gamma$ controls Hippo signaling and reciprocal NF- $\mathrm{KB}-\mathrm{YAP}$ regulation to promote colon cancer. Clin Cancer Res. 2018;24:2015-25.

20. Wang Q, Gao X, Yu T, Yuan L, Dai J, Wang W, et al. REG $\gamma$ controls Hippo signaling and reciprocal NF- $\mathrm{kB}-\mathrm{YAP}$ regulation to promote colon cancer. Clin Cancer Res. 2018;2986:2017. clincanres

21. Okamura T, Taniguchi S-i, Ohkura T, Yoshida A, Shimizu H, Sakai M, et al. Abnormally high expression of proteasome activator- $\gamma$ in thyroid neoplasm. J Clin Endocrinol Metab. 2003;88:1374-83.

22. Millet C, Yamashita M, Heller M, Yu L-R, Veenstra TD, Zhang YE. A negative feedback control of transforming growth factor- $\beta$ signaling by glycogen synthase kinase 3-mediated Smad3 linker phosphorylation at Ser-204. J Biol Chem. 2009;284:19808-16.

23. Reddi HV, Kumar A, Kulstad R. Anaplastic thyroid cancer-an overview of genetic variations and treatment modalities. Adv Genom Genet. 2015;5:43-52.

24. Li X, Zhuang J, Zhang K, Liu Y, Dong A. Galunisertib, a TGF- $\beta$ receptor (T $\beta R$ )-I inhibitor, suppresses growth and invasion of an anaplastic thyroid cancer $8505 \mathrm{C}$ cell in vitro and in vivo. Int J Clin Exp Pathol. 2016;9:7050-9.

25. Papageorgis P. TGF $\beta$ signaling in tumor initiation, epithelial-tomesenchymal transition, and metastasis. J Oncol. 2015; 2015:587193.

26. Ma R, Bonnefond S, Morshed SA, Latif R, Davies TF. Stemness is derived from thyroid cancer cells. Front Endocrinol. 2014;5:114.

27. Kubiczkova L, Sedlarikova L, Hajek R, Sevcikova S. TGF- $\beta$-an excellent servant but a bad master. J Transl Med. 2012;10:183.

28. Syed V. TGF- $\beta$ Signaling in Cancer. J Cell Biochem. 2016;117:1279-87.

29. Papageorgis P, Cheng K, Ozturk S, Gong Y, Lambert AW, Abdolmaleky HM, et al. Smad4 inactivation promotes malignancy and drug resistance of colon cancer. Cancer Res. 2011;71:998-1008.

30. Voorneveld PW, Kodach LL, Jacobs RJ, Liv N, Zonnevylle AC, Hoogenboom JP, et al. Loss of SMAD4 alters BMP signaling to promote colorectal cancer cell metastasis via activation of Rho and ROCK. Gastroenterology. 2014;147:196-208. e113.

31. Liu J, Cho S-N, Akkanti B, Jin N, Mao J, Long W, et al. ErbB2 pathway activation upon Smad4 loss promotes lung tumor growth and metastasis. Cell Rep. 2015;10:1599-613.

32. Derynck R, Zhang YE. Smad-dependent and Smad-independent pathways in TGF- $\beta$ family signalling. Nature. 2003;425:577.

33. Yan X, Liao H, Cheng M, Shi X, Lin X, Feng X-H, et al. Smad7 protein interacts with receptor-regulated Smads (R-Smads) to inhibit transforming growth factor- $\beta$ (TGF- $\beta$ )/Smad signaling. J Biol Chem. 2016;291:382-92.

34. Yu Y, Gu S, Li W, Sun C, Chen F, Xiao M, et al. Smad7 enables STAT3 activation and promotes pluripotency independent of TGF- $\beta$ signaling. Proc Natl Acad Sci. 2017;114:10113-8.

35. Altmann A, Markert A, Askoxylakis V, Schning T, Jesenofsky R, Eisenhut $\mathrm{M}$, et al. Antitumor effects of proteasome inhibition in anaplastic thyroid carcinoma. J Nucl Med. 2012;53:1764.

36. Mehta A, Zhang L, Boufraqech M, Zhang Y, Patel D, Shen M, et al. Carfilzomib is an effective anticancer agent in anaplastic thyroid cancer. Endocr Relat Cancer. 2015;22:319-29.

37. Nie J, Wu M, Wang J, Xing G, He F, Zhang L. REG $\gamma$ proteasome mediates degradation of the ubiquitin ligase Smurf1. FEBS Lett. 2010;584:3021-7.

38. Zhang Z, Fan Y, Xie F, Zhou H, Jin K, Shao L, et al. Breast cancer metastasis suppressor OTUD1 deubiquitinates SMAD7. Nat Commun. 2017;8:2116.

39. Liu L, Li D, Chen Z, Yang J, Ma Y, Cai H, et al. Wild-type P53 induces sodium/iodide symporter expression allowing radioiodide therapy in anaplastic thyroid cancer. Cell Physiol Biochem. 2017;43:905-14.

40. Liu J, Yu G, Zhao Y, Zhao D, Wang Y, Wang L, et al. REG $\gamma$ modulates p53 activity by regulating its cellular localization. J Cell Sci. 2010;123:4076-84. 